\section{Компьютерная система оценки экологической совместимости машин с лесной средой ${ }^{1}$}

\author{
Г. А. Давыдков ${ }^{2}$ \\ Петрозаводский государственный университет
}

\section{АННОТАЦИЯ}

Рассмотрен подход к решению задачи экологической совместимости лесных машин с лесной средой на основе информационных технологий.

Ключевые слова: экологическая совместимость, лесные машины, ГИС-технологии, компьютерное моделирование.

\section{SUMMARY}

Optimal choice of forest machines which should be an ecologically friendly to the forest soil is described on the basis of the GIS-technology.

Keywords: ecological compatibility, forest machines, GIS, computer aided modeling.

\section{ВВЕДЕНИЕ}

Эффективность лесозаготовок на современном уровне развития общества в значительной степени определяется степенью влияния применяемых технологий и машин на природную среду.

Повышение степени машинизации лесозаготовок и соответствующий рост их эффективности приводят к усилению техногенного воздействия лесозаготовительных процессов на лесную среду. При проведении рубок главного пользования это воздействие сводится к уплотнению почвы, разрушению почвенного покрова по следу движения машин с образованием колеи и частичной или полной минерализацией почвы. Последствия уплотнения и амелиорации участков колеи негативно сказываются на процессе лесовозобновления, что нарушает основополагающие принципы неистощимого использования возобновляемых природных ресурсов. Еще острее проблема взаимодействия лесных машин с почвой стоит при проведении выборочных рубок и рубок ухода за лесом. В этом случае помимо отмеченных отрицательных воздействий движители машин перерезают корни оставляемых на доращивание деревьев вблизи технологических коридоров. Кроме того, уплотнение почвы затрудняет рост молодых корней, что отрицательно сказывается на дальнейшем развитии древостоя и даже может привести к его гибели.

\footnotetext{
1 Работа выполнена при финансовой поддержке гранта Министерства образования РФ Т02-11.1-279

${ }_{2}^{2}$ Автор - ст. преподаватель кафедры тяговых машин (C) Г. А. Давыдков, 2003
}

Минимизации подобного вредного воздействия машин на лесную среду в последние годы уделяется значительное внимание. Эти вопросы находят свое отражение в таких важных государственных документах, как «Основные положения государственной стратегии Российской Федерации по охране окружающей среды и обеспечению устойчивого развития», «Критические технологии федерального уровня (раздел: Технологии минимизации экологических последствий трансграничных воздействий)», «Экологическая доктрина Российской Федерации». Согласно этим документам, одним из главных направлений современной государственной лесной политики является «совершенствование систем управления природными ресурсами, создание эффективных средств контроля и экологического мониторинга, повышение уровня экологической экспертизы и информационного обеспечения».

Учитывая современный уровень развития компьютерных информационных технологий, требования программ информатизации и внедрения ГИСтехнологий в лесном хозяйстве на 1999-2005 годы, решение задачи обеспечения экологической совместимости машин со средой должно базироваться на использовании достижений информационных технологий по оценке, мониторингу и прогнозированию последствий движения машин при осуществлении лесозаготовок.

\section{ЦЕЛЬ РАБОТЫ И ОБЬЕКТЫ ИССЛЕДОВАНИЯ}

Целью работы являлось повышение эффективности лесозаготовок и использования машин на основе создания и применения компьютерной системы оценки и прогнозирования экологических последствий движения машин по лесным почвам северной и средней тайги (на примере Республики Карелия).

Задачи исследования были сформулированы следующим образом:

- разработать географическую информационную систему «местность-почва» с базами данных по характеристикам почв;

- создать конечно-элементную модель взаимодействия основных типов ходовых систем машин с почвой, учитывающую специфические особенности лесных почв (слойность, пронизанность корнями, наличие камней и органических включений) [1];

- провести экспериментальную проверку адекватности разработанной конечно-элементной модели и оценить степень воздействия наиболее применяемой колесной и гусеничной техники на почвы в реальных природно-производственных условиях $[2,3]$;

- разработать компьютеризированную систему оценки, мониторинга и прогнозирования воздействия ходовых систем лесозаготовительных машин на лесные почвы;

- разработать конкретные рекомендации по областям приемлемого применения различных машин в условиях северной и средней тайги Рес- 
публики Карелия и дать рекомендации по улучшению экологической совместимости машин с природной средой.

\section{ПРИМЕНЕНИЕ ГЕОГРАФИЧЕСКИХ ИНФОРМАЦИОННЫХ СИСТЕМ ДЛЯ ОЦЕНКИ ЭКОЛОГИЧЕСКОЙ СОВМЕСТИМОСТИ} ДВИЖИТЕЛЕЙ ЛЕСНЫХ МАШИН СО СРЕДОЙ Разработанная ГИС «местность-почва» включает в себя следующие слои электронных карт и баз данных:

- «Район» - данные о границах исследуемого района, границах лесхозов и лесничеств, расположенных на его территории.

- «Населенные пункты» - данные о местоположении населенных пунктов района и информация о них.

- «Озера» - данные о положении озер на территории района и их названия.

- «Реки» - данные о положении и названия рек.

- «Дороги» - данные об автомобильной транспортной сети.

- «Железные дороги» - данные о наличии железных дорог.

- «Почвы» - данные о типах почвенного покрова, в том числе следующие: границы участков с различными типами почв, идентификатор типа почвы, название типа почвы, коэффициент несущей способности грунта, коэффициент уплотняемости грунта, максимальное значение несущей способности почвы.

- «Лесосырьевая база» - данные о лесосырьевых базах предприятий, расположенных на исследуемой территории.

- «Машины» - данные о лесозаготовительных машинах: тип, колесная формула и т.д.

В качестве топоосновы применялись карты масштабом 1:200000. Система координат - «план-схема».

Для создания системы использовались топографические карты местности, карты лесоустройства (лесхозы, лесничества, квартальная сеть), карты границ лесосырьевых баз предприятий, почвенные карты, карты четвертичных отложений [4].

Методика разработки ГИС-проекта состоит из следующих шагов.

Шаг 1. Создание электронных карт и баз данных:

- подбор программных и аппаратных средств;

- разработка электронных карт:

Шаг 2. Анализ данных:

- $\quad$ выбор критериев для анализа данных;

- $\quad$ разработка программ обработки ГБД;

- $\quad$ выявление закономерностей;

- $\quad$ математический, статистический анализ полученных результатов.
Шаг 3. Представление результатов анализа - создание карт, схем, таблиц, графиков, иллюстрирующих результаты анализа.

\section{ОЦЕНКА СТЕПЕНИ ВОЗДЕЙСТВИЯ ДВИЖИТЕЛЕЙ ЛЕСНЫХ МАШИН НА ПОЧВУ}

В предложенной компьютерной системе оценку степени воздействия движителей лесных машин на почву предлагается проводить комплексно по критериям проходимости и экологичности.

В качестве показателя проходимости машины принимается максимальная глубина колеи, при которой машина еще может осуществлять движение. Эта глубина принимается равной клиренсу машины.

Экологичность машины, наряду с ограничиваемой по глубине залегания корневой системы деревьев колеей, характеризуется уплотняемостью почв.

Алгоритм оценки воздействия машин на почву построен следующим образом:

- Определяется возможность однократного прохода машины по данному типу почв. При этом должно выполняться следующее условие:

$$
q_{y}=W / S_{\partial}<q_{\max },
$$

где $q_{y}$ - удельное давление движителя на почву; $q_{\text {max }}$ - максимальное давление, выдерживаемое почвой;

$W$ - нагрузка на колесо;

$S_{\partial}$ - действительная площадь опорной поверхности с учетом деформации грунта и движителя.

- Оценивается проходимость машины по данному виду почвы при многократных проходах по одному следу. При этом должно выполняться условие:

$$
K \geq D,
$$

где $K$ - клиренс лесозаготовительной машины; $D$ - общая деформация почвы после $n$ проходов.

- Оценивается уплотняемость почвы, которая не должна возрастать более чем на $10 \%$, поскольку подобное увеличение плотности ведет к резкому ухудшению условий развития корневых систем. За показатель воздействия принята величина $U$ :

$$
U=\omega B q_{\max }(1+\chi \ln N),
$$

где $\omega$ - коэффициент, зависящий от размера и формы опорной поверхности движителя;

$B$ - ширина движителя;

$\chi$ - знаменатель прогрессии;

$\operatorname{lgN}$ - десятичный логарифм числа повторных проходов движителя по одному следу. 
Исходные величины для расчета критериев определяются по результатам моделирования. Программа по оценке взаимодействия движителей лесных машин с почвой реализована на языке MapBASIC и встроена в оболочку пакета MapInfo. Система позволяет визуализировать результаты счета в виде таблиц и электронных карт местности (рис. 1).

По полученным значениям критериев проводится оценка возможности применения конкретной машины на данном типе почв, обоснование различных параметров ходовых систем для вновь разрабатываемых машин, проводится прогнозирование последствий применения машин. При наличии данных полевых наблюдений последствий проведенных рубок с помощью предлагаемой системы можно проводить мониторинг по оценке последствий техногенного воздействия.

\section{РЕЗУЛЬТАТЫ ИССЛЕДОВАНИЙ ЭКОЛОГИЧЕСКОЙ СОВМЕСТИМОСТИ ЛЕСНЫХ МАШИН СО СРЕДОЙ В УСЛОВИЯХ СЕВЕРНОЙ И СРЕДНЕЙ ТАЙГИ РЕСПУБЛИКИ \\ КАРЕЛИЯ}

В ходе полевых работ, проведенных совместно с лабораторией лесного почвоведения КарНЦ РАН, исследовались почвы и почвенный покров на территории района. Объектами исследований служили песчаные и супесчаные подзолы, болотные верховые почвы, сформировавшиеся на легкой песчаной и супесчаной морене, а также на флювиогляциальных отложениях в сосновых лесах различных типов и на

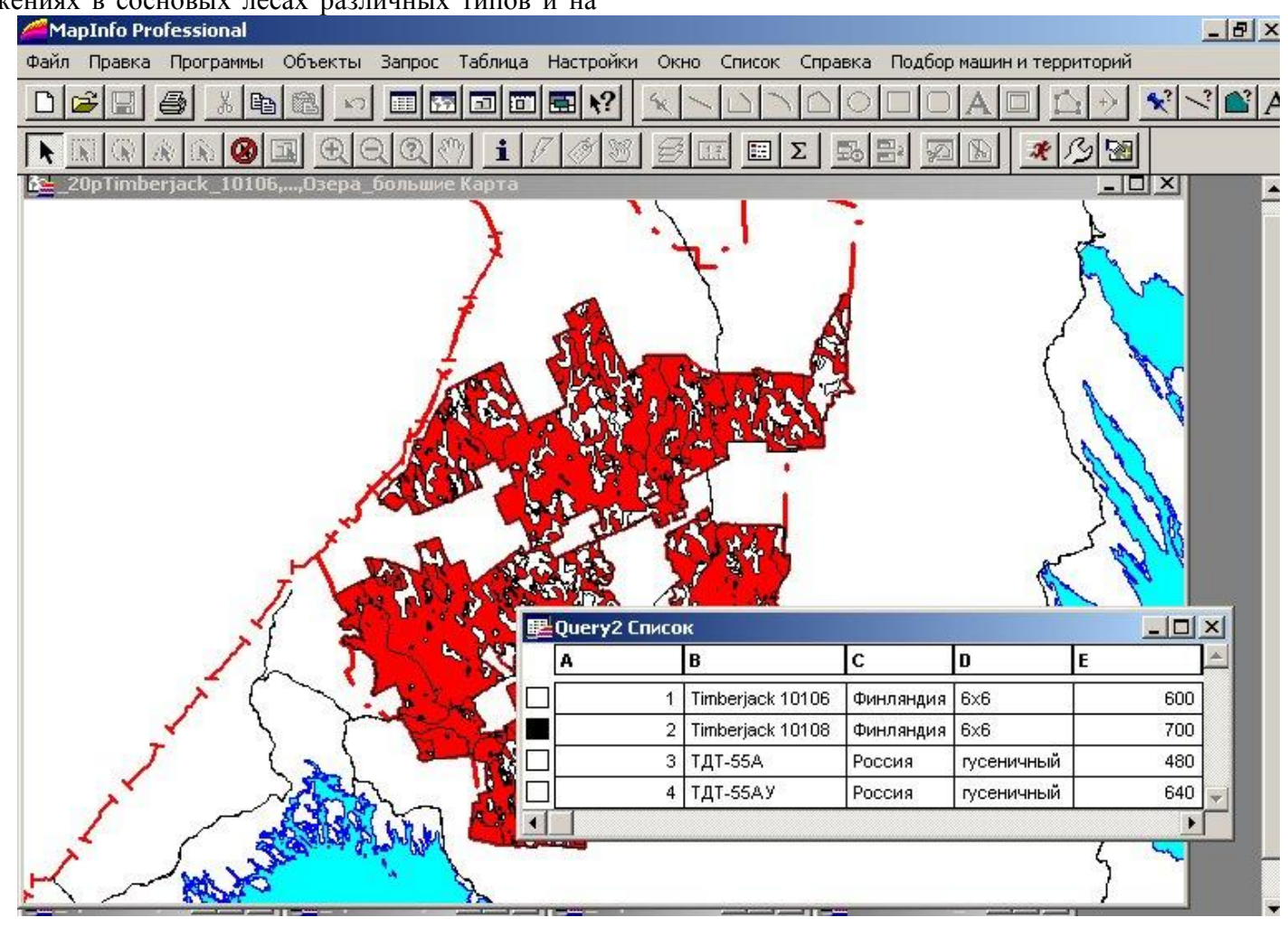

Рис. 1. Результат анализа. Карта территории и список машин, возможных для применения на ней вырубках. Согласно принятой классификации, на территории района были выделены 11 типов почв. Для каждого типа определялись основные характеристики (механический состав, плотность, плотность твердой фазы, кислотно-щелочной состав, содержание гумуса).

Данные по характеристикам почв были сведены в электронные базы данных с созданием электронной почвенной карты района.

С помощью созданной системы была исследована совместимость тракторов ТДТ-55А и Timberjack1010 с лесными почвами. Исследования взаимодействия проводились по трем направлениям: 1 - проходимость и колееобразование, 2 - уплотняемость почв, 3 - проходимость, колееобразование и уплотняемость. Анализ проходимости исследуемых тракторов для почв лесосырьевой базы предприятий Суоярвского района показывает, что колесные трактора Timberjack-1010 могут применяться на большинстве территории - порядка $73 \%$ площади (см. рис. 2). $27 \%$ площади лесосырьевой базы занимают болота и участки местности с грунтами с низкой несущей способностью.

Трактор ТДТ-55А вызывает большее колееобразование и может применяться на меньшей площади порядка $60 \%$. 

Проведенные исследования показывают, что колесные трактора оказывают более щадящее воздействие на лесные почвы по критерию колееобразования (рис. 3, на данном рисунке цифрами обозначены типы грунтов).

Гусеничный трактор ТДТ-55А без ограничения может применяться только на грунтах с высокой несущей способностью (грунты № 1 и 5, см. рис. 4). Для грунтов № 2 и 11 возможен одно-, двухкратный проход трактора до образования колеи глубиной 20 см. Колесный трактор Timberjack-1010 может быть использован на большем количестве различных почв. Его без ограничений можно эксплуатировать на почвах № 1 и 5, на почвах № 4 и 11 возможны 15-17 проходов. На участках с почвами с невысокими несущими способностями № 2, 3, 7 возможны 10-15 проходов, что достаточно для промежуточных рубок при небольших размерах выделов.
При учете обоих критериев (и проходимости, и уплотняемости) колесные трактора Timberjack-1010 могут применяться на $65,4 \%$ лесосырьевой площади района, а трактор ТДТ-55А - на 59,5\% при 20 проходах.

Разработанная система позволяет производить оценку целесообразности применения тех или иных конструктивных решений по повышению эффективности применения техники. Так, увеличение ширины гусеницы трактора ТДТ-55А с 480 мм до 640 мм приводит к увеличению зоны применяемости трактора на 5,9\%.

Применение для Timberjack-1010 более широких шин размерностью 700-26,5 вместо стандартных 600-26,5 не ведет к увеличению зоны проходимости, но в то же время приводит к уменьшению зоны применяемости из-за достижения гранично допустимого предела по критерию уплотняемости (рис. 5).

Проведенные исследования по оценке уплотняющего воздействия тракторов на почвы показывают, что гусеничный трактор ТДТ-55А может применяться на $68 \%$ площади лесосырьевой базы района, а трактор Timberjack-1010 - примерно на $65 \%$.

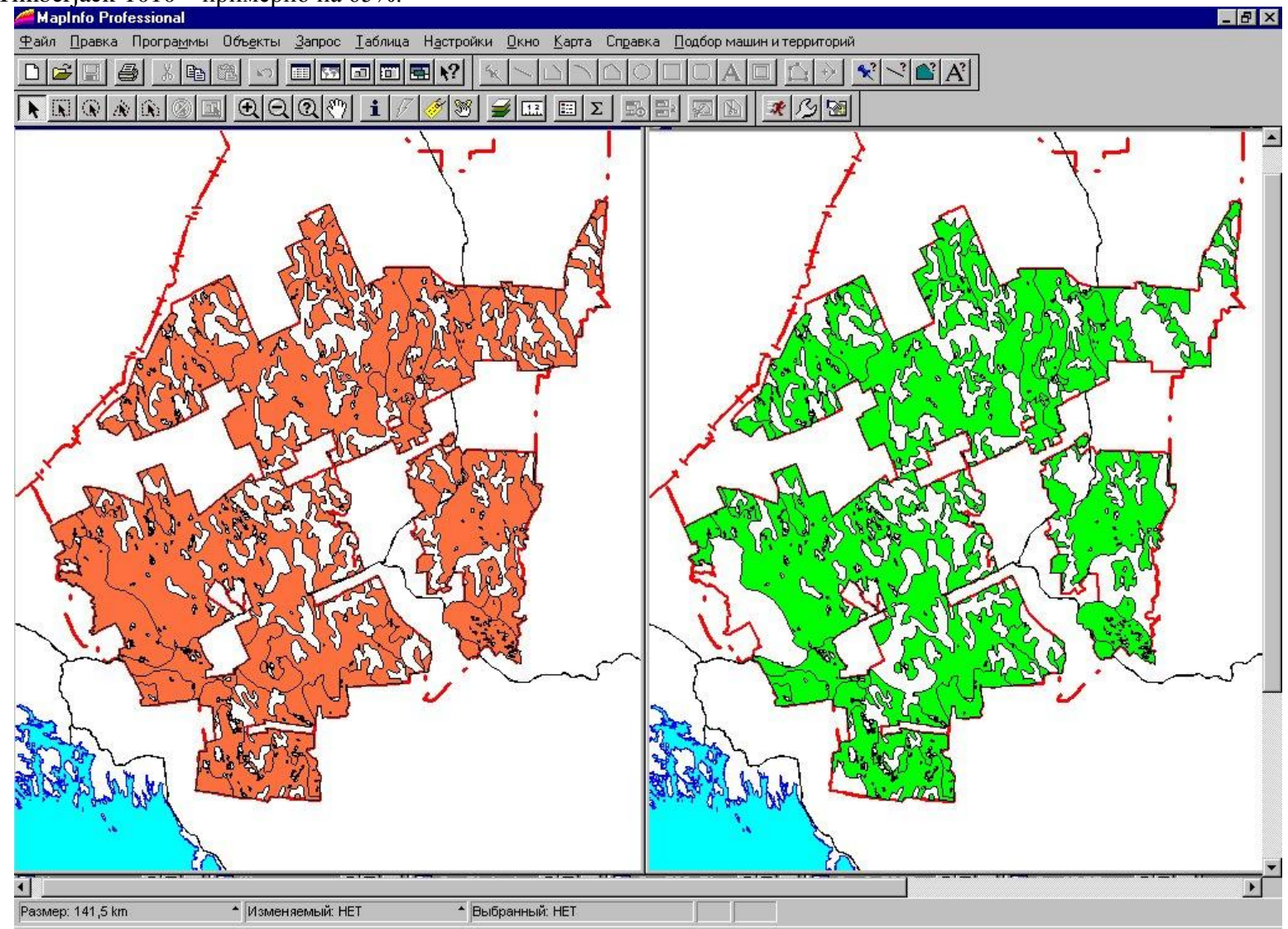

Рис. 2. Оценка возможности применения тракторов Timberjack-1010 (слева) и ТДТ-55А (справа) по условию проходимости при 20 проходах 


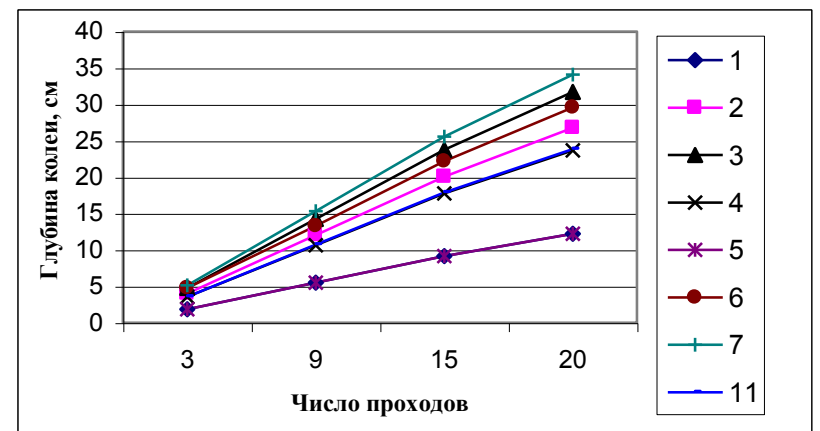

Рис. 3. Зависимость глубины колеи от числа проходов для трактора Timberjack-1010

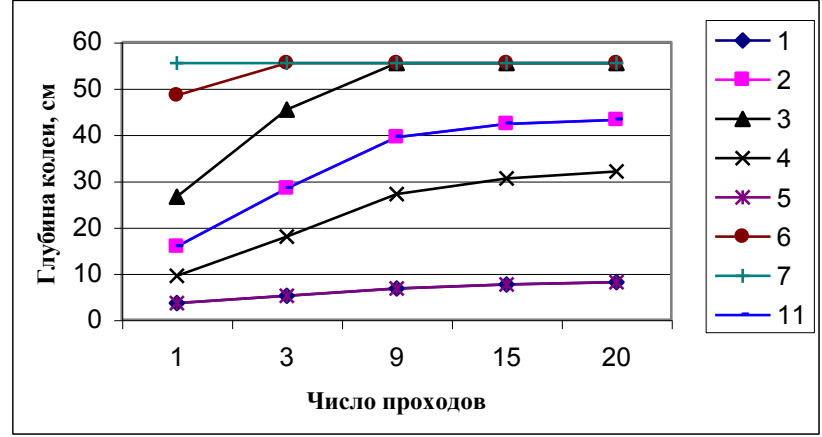

Рис. 4. Зависимость глубины колеи от числа проходов для трактора ТДТ-55А

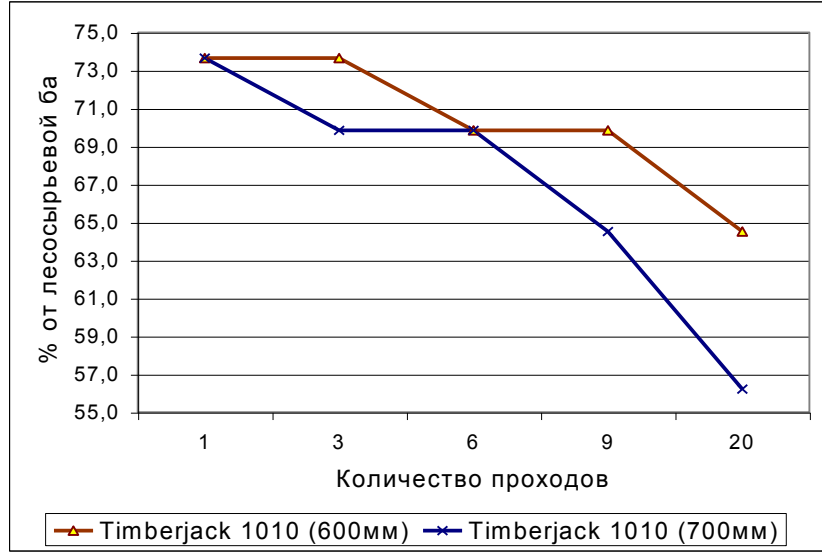

Рис. 5. Оценка возможности применения тракторов Timberjack-1010 в зависимости от ширины шины и числа проходов по двум критериям

\section{СПИСОК ЛИТЕРАТУРЫ}

1. Давыдков Г. А. Исследование взаимодействия движителей с лесной почвой на основе метода конечных элементов // Новые технологии и устойчивое управление в лесах Северной Европы: Тез. докл. межд. конф., посвященной 50 летию ЛИФа ПетрГУ. Петрозаводск, 2001. С. 40-41.

2. Давыдков Г. А., Сюнёв В. С., Кильпеляйнен С. А., Кильюнен Н., Йохиахо А. Сравнительные испытания воздействия машин на лесной участок (колееобразование) // Теоретические и экс- периментальные исследования машин и механизмов лесного комплекса: Межвуз. сб. / СПбГЛА. СПб., 2000. С. 139-144.

3. Давыдков Г. А., Сюнёв В. С. Воздействие машин на лесные почвы // Труды лесоинженерного факультета ПетрГУ. Вып. 3. Петрозаводск, 2001. C. 88-91.

4. Давыдков Г. А. Почвенные и рельефные карты на базе ГИС-технологий в решении задач экологической совместимости машины и среды // Научно-методическое обеспечение лесного комплекса Карелии: Тез. докл. научнопрактической конференции докторантов и ас- 
пирантов лесоинженерного факультета ПетрГУ.

Петрозаводск: Изд-во ПетрГУ, 1999. С. 26-27. 